\title{
Jacques Revel: entre a história da historiografia e a "crise" da história social
}

\author{
Mateus Pereira*
}

Revel, Jacques. História e historiografia: exercícios críticos. Curitiba: Ed. UFPR, 2010.

O livro em questão apresenta uma das mais importantes análises sobre a história da historiografia francesa do século XX. A publicação dos textos de Revel referenda, complementa e complexifica determinadas visôes consolidadas sobre aquela que foi (e talvez ainda seja) a principal matriz historiográfica para os historiadores brasileiros. ${ }^{1}$ O autor é bastante conhecido no Brasil por seus ensaios, suas entrevistas e por suas posições institucionais, em particular por suas atuaçóes junto à revista e ao "grupo" dos $A n$ nales. ${ }^{2} \mathrm{O}$ livro pode ser lido como um retra-

\footnotetext{
${ }^{1}$ Ver, também, REVEL, Jaques. Proposiçôes: ensaios de história e historiografia. Rio de Janeiro: Eduerj, 2009.

2 Cf., por exemplo, DAHER, Andrea. Entrevista com Jacques Revel. Topoi, Rio de Janeiro, 2009; FERREIRA, Marieta de Morais. Entrevista com Jacques Revel. Revista Estudos Históricos, v. 10, n. 19, p. 121-140, 1997; GONDRA, José Gonçalves. Telescópios, microscópios, incertezas - Jacques Revel na História e na História da Educação. In: LOPES, Eliane Marta Teixeira; FILHO, Luciano Mendes de Faria. (Org.). Pensadores sociais e História da Educação. Belo Horizonte: Autêntica, 2012, p. 81-109. GUIMARÁES, Manoel Luiz Salgado. Exercendo
}

to das diversas "crises" - supostas ou reais - da produçáo histórica francesa a partir do final do século passado, em especial da história social. ${ }^{3}$

Sáo nove textos publicados em distintas ocasiōes. Sendo que o primeiro, "construçôes francesas do passado", ocupa quase cem pá-

um ofício - Entrevista com o historiador Jaques Revel. Revista História Oral, v. 5, p. 189-199, 2002. Ver, também, REVEL, Jacques. A invenção da sociedade. Rio de Janeiro: Difel, 1989; REVEL, Jacques (Org.) Jogos de escala: a experiência da microanálise. Rio de Janeiro: FGV, 1998; e REVEL, Jacques. Micro-história, macro-história: o que as variações de escala ajudam a pensar em um mundo globalizado. Revista Brasileira de Educação. v. 15, n. 45, 2010.

${ }^{3}$ De algum modo, Jacques Revel deixa de lado um importante aspecto que vem sendo destacado por outros autores, a saber: a perda de prestígio e/ou centralidade da historiografia francesa no mundo. A esse respeito, no interior dos debates sobre a história-mundo, Patrick Boucheron, por exemplo, em 2013, afirma: "atolados nas querelas suscitadas pelo embaraçoso legado braudeliano, extraviados pelas sereias da microstoria que fazia a história em migalhas, incapazes de se dar conta do quanto a França encolhera, transformada em potência mediana da historiografia, exportando sua French Theory como outros exportam conhaque ou bolsas (ou seja, como um produto de luxo para elites mundializadas), deixavam, totalmente, de responder ao chamado da Word History". BOUCHERON, Patrick. O entreter do mundo. In: BOUCHERON, Patrick; DALALANDE, Patrick. Por uma história-mundo. Belo Horizonte: Autêntica, 2015, p. 7.

DOI - http://dx.doi.org/10.1590/2237-101X016031017

* Mateus Henrique de Faria Pereira - Doutor em História pela Universidade Federal de Minas Gerais (UFMG) e professor na Universidade Federal de Outro Preto (UFOP). Ouro Preto, MG, Brasil. E-mail: matteuspereira@gmail.com. 
ginas. Esse primeiro capítulo, publicado originalmente em 1995, pretende "dar conta de uma história da historiografia" (p. 19) francesa após a Segunda Guerra Mundial. Para o autor, os Annales, mais do que uma escola, são e foram um projeto aberto a diversas solicitaçóes de determinados presentes. Segundo Revel, desde o fim da Guerra Franco-Prussiana (1870-1871) o ensino de história ganhou, por um lado, um papel cívico para reanimar a nação humilhada; e, por outro, os historiadores assumiram lugar de destaque na formação e na elaboração da política universitária francesa. Tratava-se de uma história "positivista", caracterizada pela recusa à interpretação. Para Jacques Revel, essa posiçấo constitui um traço de longa duração ainda presente na historiografia francesa, distinguindo-a, portanto, da tradição alemá.

$\mathrm{O}$ autor enfatiza que a proposta levada a cabo pelos primeiros Annales de transformar a história em uma ciência "também propunha um positivismo" (p. 29). Para o autor, o "positivismo" (o termo é utilizado em várias passagens do livro de forma pouco rigorosa), o "marxismo" e o "estruturalismo" podem ser agrupados sob o rótulo de "funcionalismo". É esse paradigma unificador do campo das ciências sociais "que parece ter pouco a pouco se abatido, sem crise aberta, durante as duas últimas décadas" (p. 79). Tal fato, aliado à dúvida que invadiu as sociedades, contribuiu para o aumento do "ceticismo sobre a ambição de uma inteligibilidade global do social, que fora o credo, implícito ou explícito, das geraçóes precedentes" (p. 79). Essas "crises" de fundo, que implicaram a revisão do lugar dos historiadores na sociedade fran- cesa, questionaram os pressupostos de um projeto baseado nas "certezas de uma história social" (p. 79).

Revel destaca que os "pais fundadores" dos Annales, Marc Bloch e Lucien Febvre, rejeitaram toda a construção teórica e epistemológica que sustentava o projeto sociológico durkheimiano. É no interior dessa perspectiva e da defesa da prevalência da história em relação às outras ciências sociais que se dá a escolha do conceito de "social" para o primeiro plano de investigação histórica: "o social está na medida das ambiçôes ecumênicas e unificadoras do programa" (p. 33). Com o objetivo de problematizar o conceito, o autor cita uma frase na qual Febvre afirma: "uma palavra tão vaga quanto 'social' [...] parecia ter sido criada para servir de ensino a uma revista que pretendia náo rodear as muralhas" (apud Revel, p. 33). O autor destaca que para os primeiros autores dessa "escola" a história permanece essencialmente empírica, em especial pelo fato de que o "social não é jamais o objeto de uma conceituação sistemática, articulada, ele é sobretudo o lugar de um inventário, sempre aberto, de relaçóes que fundam a "interdependência dos fenômenos"' (p. 36). Para Jacques Revel, a chamada segunda geração aprofunda esse "novo empirismo" ou "positivismo crítico" (p. 54) onde o "método" ganha primazia em detrimento da teoria e das condiçôes de produção históricas. Porém, desde os anos 1970, assiste-se a um conjunto de interrogaçóes sobre a disciplina e a prática historiográfica levada a cabo a partir desses pressupostos. Desde então surge (não ape- 
nas na França) uma série de tentativas para se pensar uma "nova história" do social, crítica e problemática.

O capítulo seguinte pode ser lido como um desdobramento do primeiro. Ele procura fazer uma história da noção de mentalidades na historiografia francesa, bem como dos seus usos. O grande destaque é a análise do "contextualismo" e do organicismo do projeto de uma história das mentalidades em Febvre. Podemos dizer que o argumento principal dos dois textos, em especial "Construçôes francesas do passado" — o mais importante do livro - é a de que o giro/virada crítica (tournant critique) dos Annales (entre 1988 e 1989) foi uma tentativa de propor uma resposta, um caminho ou uma solução para a "crise" da história social. ${ }^{4}$ Posição que implicou rever a ideia de interdisciplinaridade, abrindo caminho para a reflexão historiográfica e para perspectivas experimentais. Trata-se, assim, de uma defesa fundamentada das posiçóes políticas, institucionais e epistemológicas do próprio Jacques Revel, já que entre os membros do comitê de direção da revista ele foi um dos principais responsáveis pelo tournant critique dos Annales. ${ }^{5}$ É bom lembrar que os resultados desse projeto podem ser vistos, em especial, no livro organizado Bernard Lepetit, ${ }^{6}$ onde se propóe uma outra história social, e em Um percurso

\footnotetext{
${ }^{4}$ Un tournant critique? Annales ESC, Histoire et sciences sociales, n. 2, p. 291-293, 1988; Un tournant critique. Annales ESC, Histoire et sciences sociales, n. 6, p. 1371-1323, 1989.

${ }^{5}$ DELACROIX, Christian. La falaise et le rivage. Histoire du "tournant critique". Espaces Temps, n. 59/60/61, p. 86-111, 1995.

${ }^{6}$ LEPETIT, Bernard. Les formes de l'expérience. Une autre histoire sociale. Paris: Albin Michel, 1995.
}

critico: Doze exercícios de história social, do próprio Jacques Revel. ${ }^{7}$

O livro História e historiografia é composto também por três textos publicados em Um percurso crítico, a saber: "A instituição e o social", "Máquinas, estratégias e condutas", "O fardo da memória”. Eles apresentam autores e perspectivas que, do ponto de vista de Revel, ajudam a pensar alternativas à "crise" da história social: as proposições de $\mathrm{Mi}$ chel de Certeau, Michel Foucault, Edward Palmer Thompson (ainda que apareça de forma marginal no livro) e Norbert Elias, além da microanálise, dos jogos de escalas e dos estudos de caso.

O capítulo "A instituição e o social" procura pensar o "social" a partir da instituição a fim de contribuir para os "deslocamentos e as reformulaçóes decorrentes do discurso que os historiadores do social detêm sobre a instituição” (p. 117). Trata-se de criticar diversas perspectivas historiográficas que tendiam à "institucionalização do social" (p. 124) e a "oposição radical entre a instituição e o social" (p. 130). O autor exemplifica sua crítica a partir dos estudos de prosopografia social. Para ele, a maioria desses estudos restringiu-se à análise, à descrição, à uniformização e, em especial, aos estudos estritamente institucionais. Critica-se, também, a utilização de classificações sociais preestabelecidas nesses trabalhos.

Em relação à Michel de Foucault, o autor argumenta que alguns deslocamentos do itinerário do filósofo são representativos: “do

\footnotetext{
${ }^{7}$ Original francês: REVEL, Jacques. Un parcours critique. Douze essais d'histoire sociale. Paris: Galaade, 2006.
} 
modelo da máquina ao tema da 'governamentabilidade', do poder às 'relaçóes de poder”" (p. 132). Sobre a obra desse autor, Revel, em "Máquinas, estratégias e condutas", afirma que a maioria dos historiadores está satisfeita com uma leitura redutora de sua obra. Apesar disso, ou por isso mesmo, seus textos são lidos com assiduidade e fidelidade pelos historiadores há mais de quarenta anos. Ele sugere que, ao contrário de um uso que pretende restituir o sentido essencial do texto Foucault, dever-se-ia "levar em conta o conjunto dos efeitos, entendidos e mal entendidos que são como a sombra espectral de uma proposta" (p. 175).

Nessa direção, não deixa de chamar atenção uma citação de Siegfried Kracauer no ensaio consagrado a esse autor: "adoro o lado confuso do pensamento dos historiadores; ele é igualmente exato na medida em que permanece inacabado" (apud Revel, p. 184). É bastante interessante também a aproximação que Revel opera entre as perspectivas de Kracauer e as de Paul Ricoeur (Tempo e narrativa), no que se refere à heterogeneidade e incompletude da narrativa histórica. Um dos pontos altos do ensaio é a forma como o autor explora, a partir de Kracauer, a homologia entre história e fotografia. Ricoeur é convocado novamente para acompanhar a reflexão do autor sobre "recursos narrativos e conhecimento histórico". Além desse filósofo, percebemos, ao longo do livro, como a obra de Reinhart Koselleck foi importante, na França, para a reflexão historiográfica e teórica na passagem do século XX para o XXI. Em especial para criticar a ambição ingênua e simplista de certo realismo e cien- tificismo da história social francesa do século XX. Revel defenderá a experimentação da narrativa histórica como alternativa a esse tipo de história nos dois breves textos que fecham o livro. $\mathrm{O}$ primeiro sobre a questão da biografia; o outro dedicado aos estudos da memória. Ainda que vaga, a ideia de experimentação é utilizada como um elogio à ousadia e, ao mesmo tempo, como uma crítica a ideia de "método".

Para adensar a heterogeneidade do livro, a condição de testemunha dos movimentos da historiografia francesa, presente em vários textos, ganha forte destaque em " $\mathrm{Mi}$ chel de Certeau historiador: a instituição e seu contrário”. Para Revel, a instituição está presente no trabalho do autor de $A$ escrita $d a$ história para "logo ser desmentida" (p. 142), já que Certeau "não deixou de sentir-se atraído pelas produçóes inclassificáveis, pelas separaçóes, pelo trabalho contínuo de reclassificação que opera a história” (p. 142). Não haveria nas preocupaçôes desse historiador uma separação radical entre a experiência (seja individual ou coletiva) e suas formas institucionais. Para dar conta dessa complexidade emerge no vocabulário certoniano uma constelação conceitual que mobiliza uma argumentação bastante singular. Em busca de cartografias, topografias ou escalas múltiplas, ganham destaque, em sua linguagem, termos como: possibilidades políticas e sociais, confrontação (conflito e negociação), deslocamentos, passagens, perda, falta, mística, operação, criação, legitimação, autoridade, lugar, bricolagem, errância, jogos, alteridade, invenção, outro, cruzamentos, redes, desvio. "A operação historiográfica”, 
importante texto de Certeau, pode ser lido, assim, como um acontecimento geracional: um "momento em que na disciplina um 'despertar epistemológico' atesta, por várias frentes, uma 'urgência nova'” (p. 144). Na dinâmica entre o lugar ou a errância, a instituição ou seu contrário, o Certeau de Revel é mais complexo e ambíguo: "o que lhe pareceu sempre essencial e, que provavelmente, dá unidade ao seu trabalho, são os usos não institucionais da instituição" (p. 149). Certeau, dessa maneira, "náo se satisfazia nem com um regime de evidência compartilhada, nem com um regime de suspeita generalizada" (p. 145). Essa leitura do autor de "A operação historiográfica" nos ajuda a combater abusos do subjetivismo contemporâneo, já que para Michel de Certeau a produção histórica é produto de um lugar essencialmente social. O Certeau de Revel nos recorda que "o historiador se submete aos imperativos de uma profissão pela qual deve fazer conhecer e com a qual ele se encontra em negociação constante por tudo que toca suas maneiras de fazer e de dizer" (p. 145).

A heterogênea coletânea de textos de Jacques Revel nos ajuda a repensar certos passados e conceitos dominantes e estruturadores da nossa prática historiadora. Nessa direção, o livro pode contribuir para pensar questôes que o antropólogo brasileiro Eduardo Viveiros de Castro talvez tenha formulado de forma mais radical: os conceitos (e suas distinçôes implícitas) de "social" e "cultural" ainda têm pertinência? Qual a relevância de uma "antropologia [diríamos: história] social ou cultural"? As alternativas para Castro oscilam entre repensar os adjetivos que acompanham a disciplina e/ou na elaboração de uma linguagem conceitual diversa. ${ }^{8}$

Podemos dizer que a presença explícita e implícita de Michel de Certeau na obra aqui resenhada contribui para que Revel realize o exercício de criticar a historiografia dos antecessores e do seu presente para, ao mesmo tempo, construir espaços e lugares para a emergência do novo. A leitura de História e historiografia nos ajuda, portanto, a pensar nos desafios de ontem e de hoje tanto da história social como da história da historiografia. Em especial, por servir de alerta à tentação que essas subdisciplinas permanentemente vivem: a de ser considerada, por seus praticantes, a melhor - talvez até a mais verdadeira - "forma" de se escrever história. Contra essa sedução, os ensaios de Revel sugerem outros caminhos: a criatividade, a experimentação, o rigor, a erudição e a crítica.

Referências bibliográficas

BOUCHERON, Patrick. O entreter do mundo. In: BOUCHERON, Patrick; DALALANDE, Patrick. Por uma históriamundo. Belo Horizonte: Autêntica, 2015.

DAHER, Andrea. Entrevista com Jacques Revel. Topoi, Rio de Janeiro, 2009.

DELACROIX, Christian. La falaise et le rivage. Histoire du "tournant critique".

${ }^{8}$ VIVEIROS DE CASTRO, E. O conceito de "sociedade" em antropologia. In: VIVEIROS DE CASTRO, E. A inconstância da alma selvagem - e outros ensaios de antropologia. São Paulo: Cosac \& Naify, 2002, p. 297-316. 
Espaces Temps, n. 59/60/61, p. 86-111, REVEL, Jacques (Org.). Jogos de escala: a 1995. experiência da microanálise. Rio de Janeiro:

FERREIRA, Marieta de Morais. Entrevista FGV, 1998.

com Jacques Revel. Revista Estudos Históricos, v. 10, n. 19, p. 121-140, 1997.

GONDRA, José Gonçalves. Telescópios, microscópios, incertezas - Jacques Revel na História e na História da Educação. In: LOPES, Eliane Marta Teixeira; FILHO, Luciano Mendes de Faria (Org.). Pensadores sociais e História da Educação. Belo Horizonte: Autêntica, 2012.

GUIMARÃES, Manoel Luiz Salgado. Exercendo um ofício - Entrevista com o historiador Jaques Revel. Revista História Oral, v. 5, p. 189-199, 2002.

LEPETIT, Bernard. Lesformes de l'expérience. Une autre histoire sociale. Paris: Albin Michel, 1995.
- A invenção da sociedade. Rio de Janeiro: Difel, 1989. - Micro-história, macro-história: o que as variaçóes de escala ajudam a pensar em um mundo globalizado. Revista Brasileira de Educação, v. 15, n. 45, 2010. . Un parcours critique. Douze essais d'histoire sociale. Paris: Galaade, 2006. . Proposiçóes: ensaios de história e historiografia. Rio de Janeiro: Eduerj, 2009. VIVEIROS DE CASTRO, E. O conceito de "sociedade" em antropologia. In: VIVEIROS DE CASTRO, E. A inconstância da alma selvagem - $e$ outros ensaios de antropologia. São Paulo: Cosac \& Naify, 2002. p. 297-316. 